\title{
Clinical Dilemma and the Role of Cone-Beam Computed Tomography in the Diagnosis of an Unusual Presentation of Central Odontogenic Tumor-A Case Report
}

\author{
Mouttoukichenin Surenthar ${ }^{1}$ Subramanian Vasudevan Srinivasan ${ }^{1}$ Vannathan Kumaran Jimsha ${ }^{1}$ \\ Ramanathan Vineeth ${ }^{1}$ \\ ${ }^{1}$ Department of Oral Medicine and Radiology, Mahatma Gandhi \\ Postgraduate Institute of Dental Sciences, Puducherry, India \\ Indian J Radiol Imaging 2021;31:782-788. \\ Address for correspondence Mouttoukichenin Surenthar, \\ Department of Oral Medicine and Radiology, Mahatma Gandhi \\ Postgraduate Institute of Dental Sciences Pondicherry, Puducherry \\ (U.T.), India (e-mail: msurentharm@gmail.com).
}

\author{
Abstract \\ Keywords \\ - ameloblastoma \\ - cone beam computed \\ tomography \\ - exophytic \\ - plexiform
}

Cone beam computed tomography (CBCT) provides a detailed analysis of the dentition and of cortical and medullary bone free of superimposition inherent in radiographs, which are effortlessly plausible, easily available, and relatively inexpensive when compared with other cross-sectional imaging modalities such as computed tomography (CT) and magnetic resonance imaging (MRI). This article presents a case report of a 23-year-old male patient with a complaint of a mass in the right side lower back tooth region for the past 2 and a half months, which had the unusual presentation of prominent exophytic growth masking the central odontogenic tumor, wherein the diagnostic performances of CBCT in unveiling the diagnostic challenge that led to the clinical dilemma is emphasized. Routine radiographs such as orthopantomogram, mandibular occlusal view were taken along with $\mathrm{CBCT}$, which accentuated the precise diagnosis in this case. The lesion was surgically enucleated with curettage and extraction of the involved teeth. CBCT unveiled the classic multilocularity of ameloblastoma, which routine imaging failed to display. CBCT played a pivotal role in counteracting the diagnostic challenges faced and also in distinguishing it from a cystic lesion that was initially deceived by routine two-dimensional radiographs.

\section{Introduction}

Three-dimensional imaging (3D) in the field of dentistry was evolved to meet the demands of advanced technologies in diagnosis and also to decide upon various treatment strategies that pose both diagnostic and surgical challenges. Cone-beam computed tomography (CBCT) with its copious applications is a more convincing diagnostic tool as this imaging modality eliminates limitations of two-dimensional
(2D) radiography such as superimpositions, distortions, etc. ${ }^{1}$ CBCT can visualize the outline of the skin and also the mucosal outline of the pharynx and oral cavity though lacks soft tissue contrast resolution. It allows clinicians to view and appreciate the lesion in three-dimensional architecture thoroughly than plain radiographs such as panoramic, lateral cephalometric, and anterior-posterior projections. ${ }^{2}$ СВCT can provide a detailed examination of hard tissue findings.
DOI https://doi.org/ 10.1055/s-0041-1736401. ISSN 0971-3026.

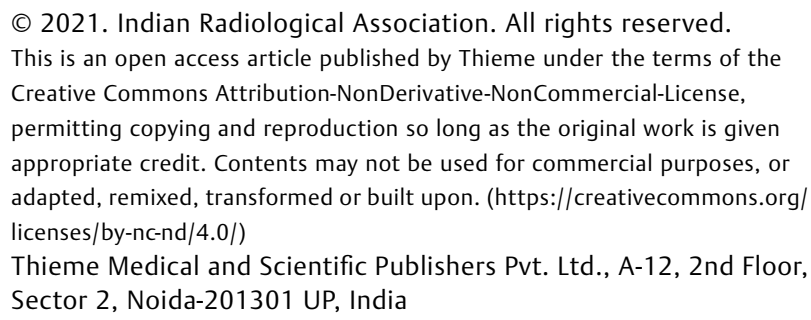


CBCT may especially be useful in distinguishing the desmoplastic subtype of ameloblastoma from other types as it contains coarse internal calcifications as well as the destruction of surrounding cortices.

Ameloblastoma is a tumor of benign, but aggressive nature of odontogenic origin. Robinson in 1937, defined ameloblastoma as "usually unicentric, nonfunctional, intermittent in growth, anatomically benign, and clinically persistent." According to the update from the $4^{\text {th }}$ edition of the World Health Organization Classification of Head and Neck Tumors on Odontogenic and Maxillofacial Bone Tumors in 2017, ameloblastomas are classified under benign odontogenic tumors of epithelial origin, and the classification has been simplified and narrowed to ameloblastoma, unicystic ameloblastoma, and extraosseous/peripheral types. ${ }^{3}$ The involvement of mucosa in solid intraosseous ameloblastoma is a rare secondary phenomenon, and if it occurs, it is often confused with peripheral exophytic lesions such as peripheral giant cell granuloma and peripheral ossifying fibroma. $\mathrm{Kuru}^{4}$ in 1911, first reported the case of intraosseous ameloblastoma manifesting as a peripheral exophytic lesion. Intraosseous ameloblastoma originates from a central lesion of the jawbone, proliferates locally, and may infiltrate the cancellous marrow spaces expanding the bone rather than perforating it. But very rarely, the central type of ameloblastoma may tend to perforate the cortex of the bone to penetrate and present as extraosseous exophytic growth of the gingiva or over the adjacent alveolar mucosa. This article discusses such a rare and abovementioned unusual clinical presentation, which probably to the best of our knowledge would be the eighth reported case in the literature. Informed consent for the images or other clinical information relating to this case was obtained from the patient.

\section{Case History}

A 23-year-old male patient reported to the Department of Oral Medicine and Radiology with a chief complaint of swelling in the right lower back teeth gum region for 2 and a half months. The patient had noticed the swelling 2 and a half months back which was initially small in size and gradually increased to the presented size. The swelling was not associated with pain, numbness, or paraesthesia, and there was no history of trauma. There were no harmful habits in his personal history. All vitals were within normal limits. On extraoral examination, there was a mild facial asymmetry with a diffuse swelling on the right lower third of the face, which was measuring approximately $3 \times 4 \mathrm{~cm}$ in size. The overlying skin appeared normal with no visible pulsations and no secondary surface changes such as sinus opening or pus discharge. On palpation, the swelling was firm in consistency and nontender with no local rise in temperature, and it was nonfluctuant, nonpulsatile, noncompressible, and nonreducible (-Fig. 1). Two right submandibular lymph nodes of size roughly measuring less than $0.5 \mathrm{~cm}$ were enlarged, oval in shape, firm in consistency, mobile, and nontender.

On intraoral examination, a proliferative sessile exophytic growth of size approximately $4 \times 1 \mathrm{~cm}$, was present in the

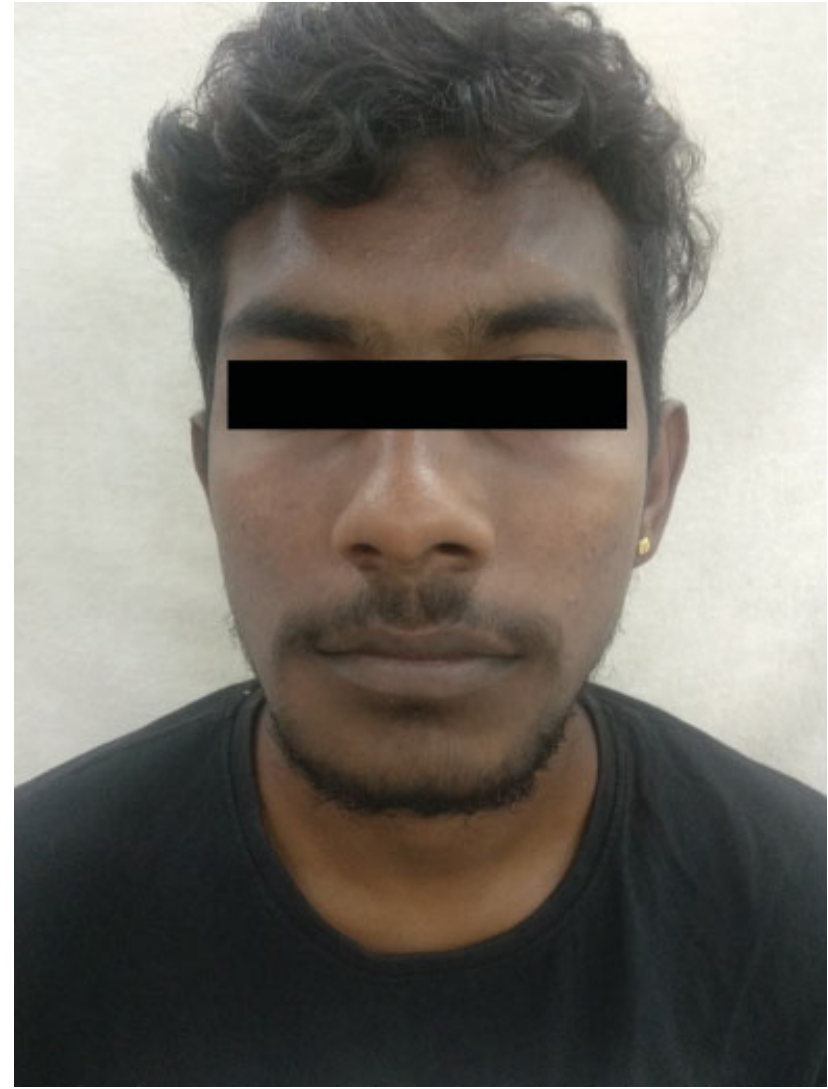

Fig. 1 Extraoral view showing mild facial asymmetry.

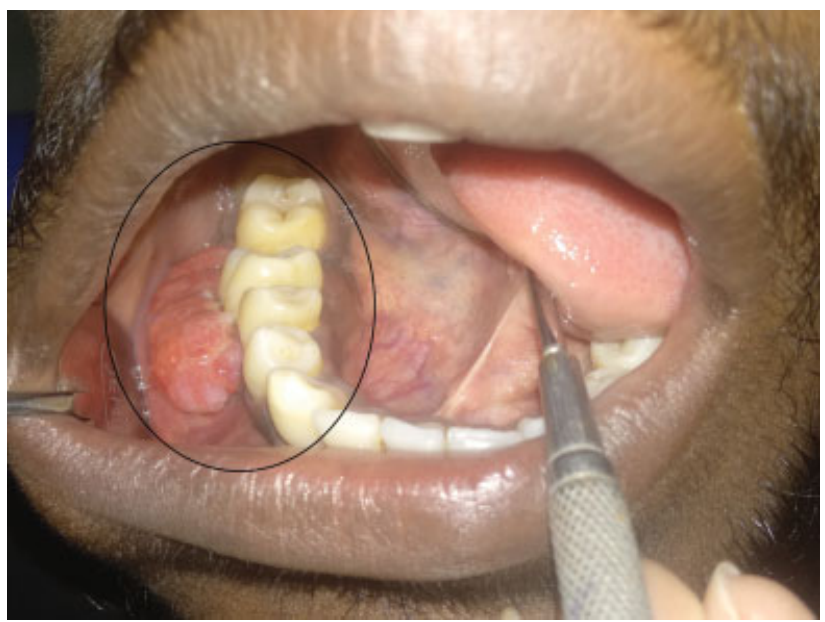

Fig. 2 Intraoral view showing the exophytic gingival growth.

buccal aspect of the marginal gingiva of 45,46 , and 47 , red in color with the lobulated surface. The growth is firm and nontender with no visible pus discharge or bleeding (-Fig. 2). There was evidence of bicortical expansion from 44 to 47 with obliteration of the buccal vestibule from 45 to 47 (-Fig. 3).

Grade III mobility was elicited in 45,46 , and 47 with a displacement of the crown of 45,46 from normal alignment (-Fig. 3). The oral hygiene status was fair. On the basis of history and clinical examination, we inferred a provisional diagnosis of peripheral exophytic growth most probably 


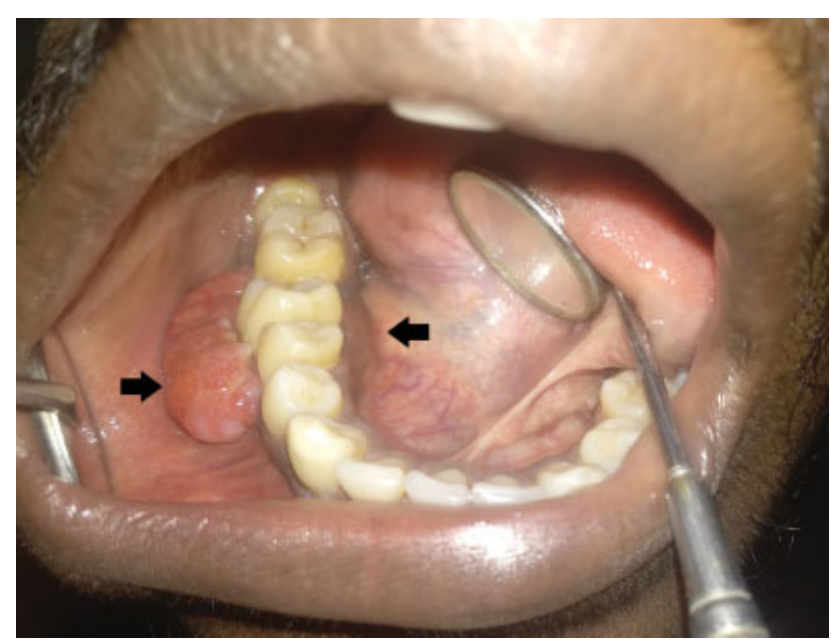

Fig. 3 Bicortical expansion with a displacement of 46 .

pyogenic granuloma. However, an exophytic growth would not cause bicortical expansion or grade III mobility and displacement of adjacent teeth, which made this case arrive into a clinical dilemma with a suspicion to think in terms of malignancy such as squamous cell carcinoma or osteosarcoma. Considering the location and severity, ameloblastoma and central giant cell granuloma were considered in the differential diagnosis.

\section{Investigations}

Routine hematological investigations revealed no significant findings and were within normal limits.

Orthopantomogram revealed a well-defined unilocular radiolucency extending from mesial of 44 to distal of 47 with an evidence of knife-edge type of root resorption in 44 , 45 , and 47 and complete root resorption up to the cervical third of crown in 46 with scalloped corticated borders in the inferior aspect along the inferior border of the mandible and right mandibular nerve canal displaced downward (-Fig. 4).

The mandibular right lateral occlusal view revealed significant expansion of the buccal cortex which was less pronounced on the lingual aspect (-Fig. 5).

CBCT axial section revealed a well-defined multilocular hypodense region extending from distal of 43 to distal of 47 with evidence of buccal and lingual cortical plate expansion

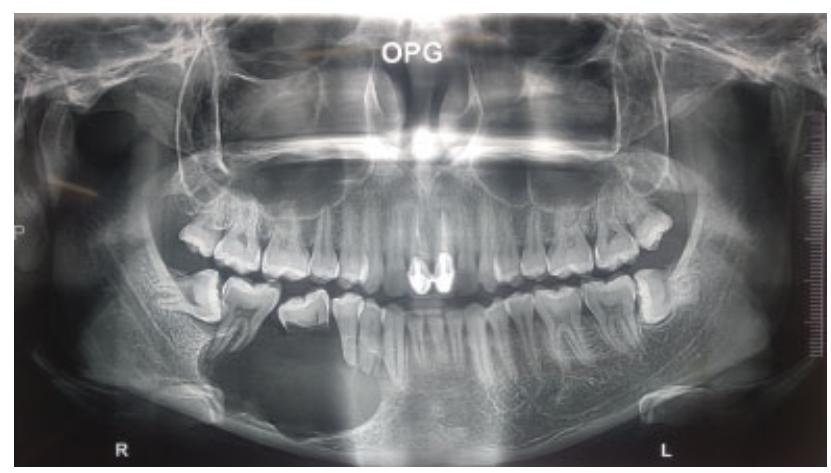

Fig. 4 Panoramic view: well-defined unilocular lesion with corticated borders and resorption of roots.

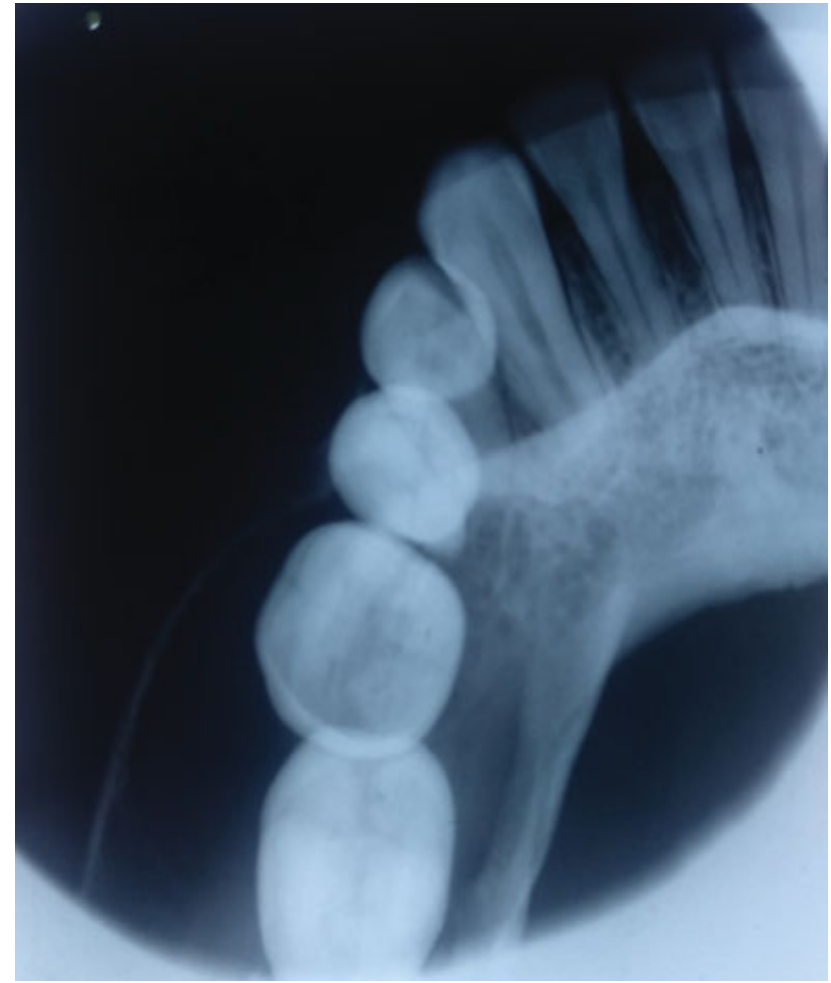

Fig. 5 Lateral mandibular occlusal view: bicortical expansion without perforation of cortex.

and thinning with perforation on a buccal plate in 44 and 47 regions (-Fig. 6A). The axial section also showed a single, straight, complete, and thick septa at the level of the middle third of the root of 44 (-Fig. 6B) that was recognized to separate the tumor into large and small compartments, anterior and posterior to 44 . Coronal section showed loss of superior boundary of right inferior alveolar nerve canal with knife-edge type root resorption in 44,45 , and 47 . There was complete root resorption extending up to the cervical third of the crown in 46 ( $\mathbf{- F i g}$. $\mathbf{6 C}$ ). The sagittal section revealed tilting of the crown of 46 to distal aspect ( - Fig. 6D). The $3 \mathrm{D}$ reconstruction revealed through and through perforation of the buccal and lingual cortical plates with the intact inferior border of the mandible ( - Fig. $6 \mathbf{6 E}$ ).

$\mathrm{H} \&$ E-stained section from an incisional biopsy of the intraoral exophytic growth exhibited network of odontogenic epithelium forming a plexiform pattern and reverse polarity of peripheral cells with extensive inflammatory reaction suggesting a plexiform type of ameloblastoma with dysplastic features. However, excisional biopsy sections from the noninflammatory area were advised for the final diagnosis. The lesion was surgically enucleated with curettage and extraction of the involved teeth $42,43,44,45,46,47$, and 48 (-Fig. 7) under general anesthesia.

$\mathrm{H} \&$ E-stained section from excisional biopsy exhibited a network of the odontogenic epithelium with clear distinction of peripheral and central cells. The peripheral cells showed reversal of polarity in occasional areas, and the central cells of the network showed a stellate type of cells with areas of cystic degeneration in the connective tissue stromal area (-Fig. 8). The histopathology of the lesion was confirmative 

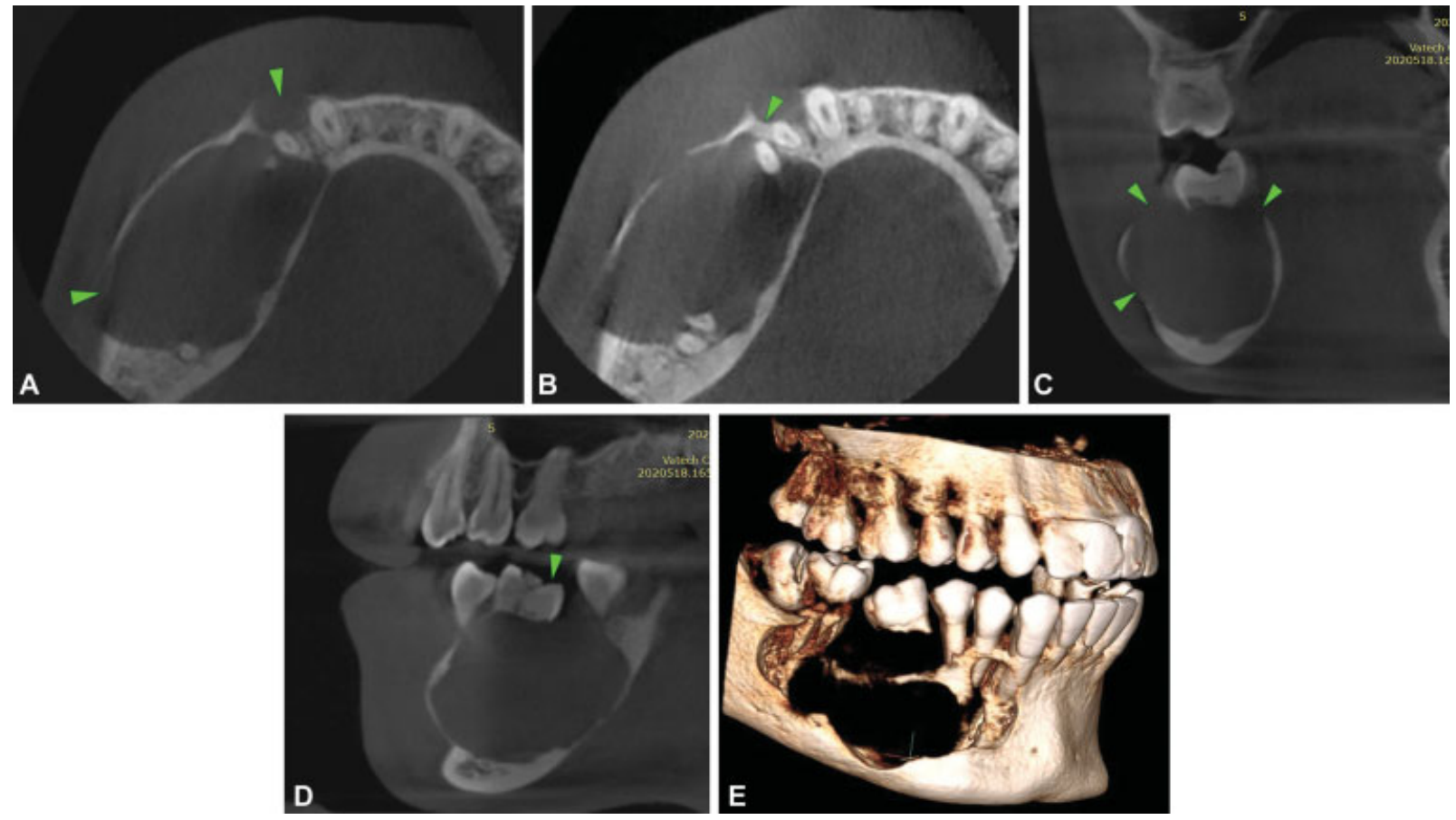

Fig. 6 (A) CBCT axial view showing a well-defined multilocular hypodense lesion with bicortical expansion and perforation of the buccal cortex marked in green arrows. (B) CBCT axial view showing single, straight, complete, and thick septa marked in green arrow. (C) CBCT coronal view showing perforation of cortex with resorption of root of 46 marked in green arrows. (D) CBCT sagittal view showing periapical hypodense lesion with tilting of 46 to the distal aspect marked in green arrow (E). CBCT 3D reconstruction view showing through and through the perforation of buccal and lingual cortex. $\mathrm{CBCT}$, cone beam computed tomography.

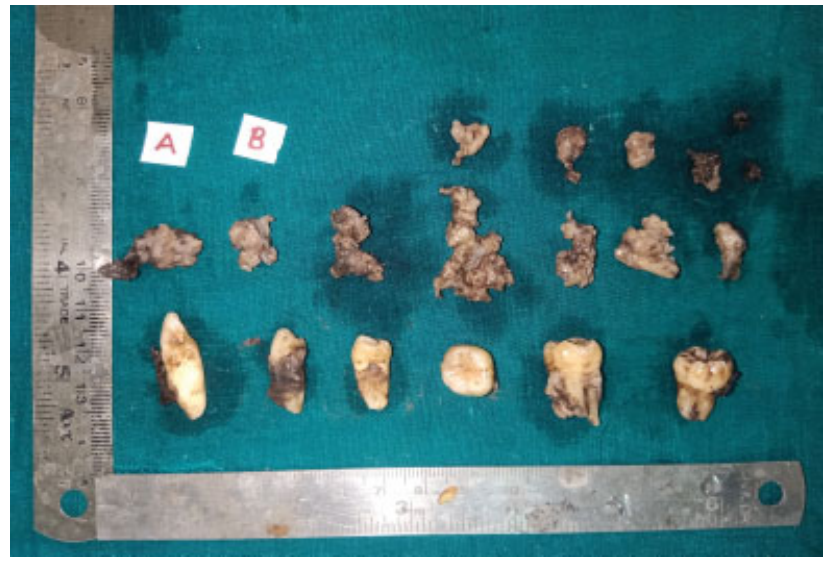

Fig. 7 Gross view of surgically enucleated and curetted lesion with the extraction of involved teeth.

of "plexiform type of ameloblastoma." The patient was followed up after marginal mandibulectomy of the involved lesional site. Immediate short-term follow-up after 1 week from the day of surgery showed satisfactorily healing surgical site with a complaint of numbness of the lower lip, which was probably due to iatrogenic injury to the mandibular nerve. Later after 4 months, long-term followup revealed a completely healed surgical site ( - Fig. 9) with reversal of lost sensations to the lower lip. The patient will be further planned for prosthetic rehabilitation of the surgical defect and missing teeth so as to improve his masticatory function.

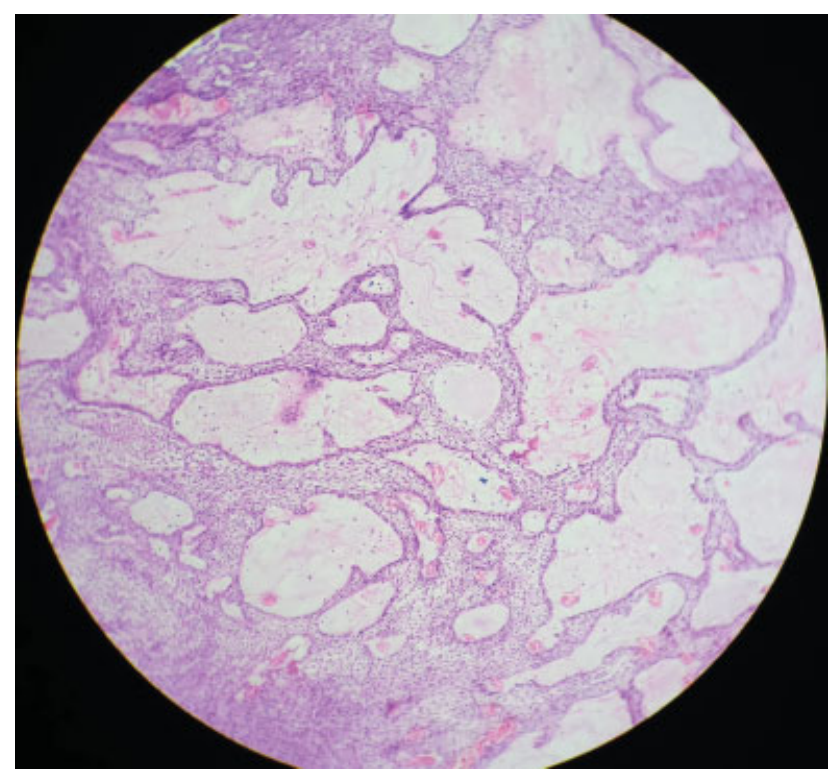

Fig. $8 \mathrm{H}$ - and E-stained section exhibiting plexiform ameloblastoma.

\section{Discussion}

Ameloblastoma is a slow growing, locally aggressive, and benign epithelial odontogenic tumor, which accounts for $10 \%$ of all odontogenic tumors in the jaw. This conventional type is particularly seen in young adults with a median age of 35 years with no specific gender predilection. About $80 \%$ of these cases occur in the mandible frequently in the posterior 


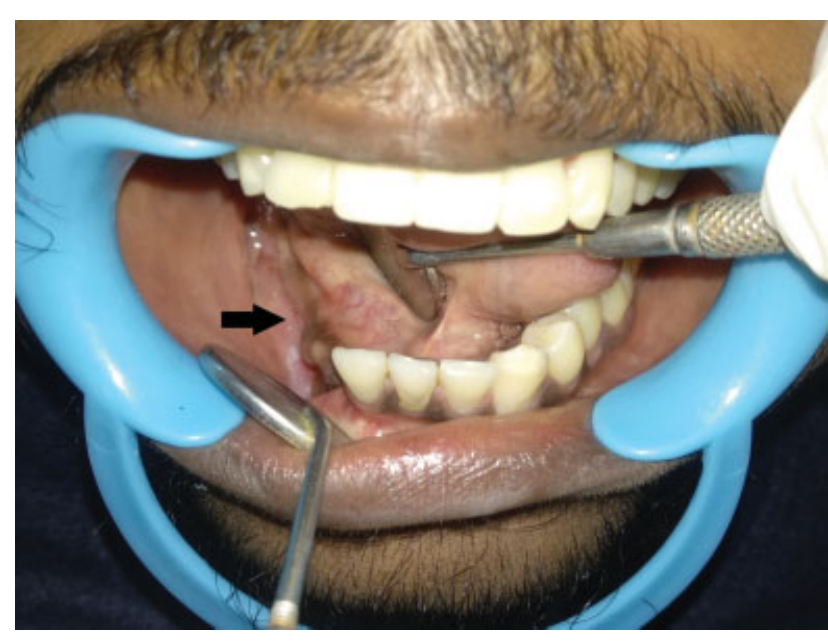

Fig. 9 Long-term follow-up showing completely healed surgical defect with missing teeth 42 to 48 .

region. ${ }^{5}$ Histologically, it displays two distinct types: follicular and plexiform. In the plexiform ameloblastoma, the ameloblast-like tumor cells are arranged in irregular masses, or as a network of interconnecting strands of cells and sometimes double rows of columnar cells are lined up back-to-back. $^{6}$

The existence of peripheral (soft tissue location) forms of ameloblastoma is well documented though rare. However, ameloblastoma exhibiting as soft tissue gingival overgrowth is a rare phenomenon. $\mathrm{Kuru}^{4}$ in 1911, reported the first case of intraosseous ameloblastoma manifesting as a peripheral (exophytic) lesion. Later, two similar cases were reported by Tongdee and Ganggakavin and Stevenson and Austin respectively, probably very few similar cases have been reported in the English literature. ${ }^{7}$ CBCT imaging is highly useful in revealing regions of perforation of the expanded cortical plate as a result of the inability of the production of periosteal new bone to keep up with the rate of growth of the expanding ameloblastoma.

In our case, most of the clinical features were favorable for the diagnosis of peripheral exophytic lesions such as pyogenic granuloma or peripheral giant cell granuloma.

However, effects on surrounding structures such as tooth mobility, displacement, and cortical expansions are uncommon with these exophytic lesions, which enunciated a clinical dilemma in this case. There were no carious teeth in the involved region to think in terms of radicular cyst nor was there any missing tooth in that quadrant to consider dentigerous cyst. An odontogenic keratocyst does not expand the bone to this degree, and hence the mere consideration of malignancies such as squamous cell carcinoma or osteosarcoma could not be ruled out. A radiological dilemma arose after the orthopantomogram, which revealed a well-defined unilocular radiolucency with sclerotic borders suggestive of cystic lesions with significant root resorption thereby ruling out malignancy. Bicortical expansion with thinning of the buccal plate without perforation was seen in the lateral occlusal view. To have an unambiguous radiographical finding and also to ratify whether the peripheral exophytic growth is an independent lesion or extension from the central lesion within the bone, CBCT was recommended.

CBCT unveiled the multilocularity of the lesion with breaching of the buccal cortical plate causing perforation through which the lesion had proliferated as an exophytic growth over the gingiva. Further, Hounsfield units (HU) derived from greyscale values of CBCT, traced few areas of cyst-like component (3.9 to $22.9 \mathrm{HU}$ ) and major areas with tumor components ( 35.9 plus/minus $12.6 \mathrm{HU}$ ) which clearly depicted that the lesion would probably be the result of cystic degeneration which was later confirmed in the histopathological report. ${ }^{8,9}$ This finally convinced the diagnosis of an intraosseous odontogenic tumor masquerading with a peripheral exophytic growth, proved in the histopathological sections as plexiform ameloblastoma. Sanjay et $\mathrm{al}^{7}$ reported a similar case in a 45-year-old male patient in the same location. Kiran Holikatti et $\mathrm{al}^{10}$ and Tabatabaei et $\mathrm{al}^{11}$ reported ameloblastomas presenting as gingival enlargement with an unusual presentation in 50-year-old female and 41-year-old female patients, respectively, at the third molar region. But in all three of the abovementioned cases, routine $2 \mathrm{D}$ imaging itself depicted multilocular radiolucency (soap bubble appearance) although there was no bicortical expansion and clued the diagnosis in favor of odontogenic cyst or tumor, which was clinically well relatable without posing clinical or radiodiagnostic dilemma. However, unilocular radiolucency with buccal cortex expansion mimicking our case was reported by Shetty et $\mathrm{al}^{12}$ as central plexiform ameloblastoma with exophytic growth, but in the anterior mandible in a 11-year-old patient. A complete review of all the seven cases reported so far in the literature along with the present case with all details is represented in the table below ( $\mathbf{- T a b l e ~} \mathbf{1}$ ).

Although peripheral ameloblastoma and peripheral intraosseous ameloblastoma exhibit similar clinicopathological features presenting as an exophytic soft-tissue lesion, the difference in their biological behavior often challenges diagnosis. ${ }^{13}$ This is where CBCT plays a pivotal role in clearly demarcating the penetration of intraosseous tumor from inside by perforating the buccal cortical plate thus eliminating peripheral ameloblastoma, which is completely superficial and seldom causes bone infiltration, even before confirming it through histopathological criteria.

This presented case is rare in literature because of the age that it was seen in a young patient ( 23 years old) and the ability of the lesion to penetrate the periosteum and breach through the overlying epithelium presenting into an unusual prominent exophytic growth thus exhibiting a diagnostic challenge both clinically and radiographically.

To conclude, the presentation of such tumors with an exophytic lesion could always be a diagnostic challenge and would invite all possible confusions to consider the most common exophytic lesions and the rare peripheral ameloblastoma. Thus, CBCT provides all accessory information when compared with conventional panoramic radiography about the extent, borders, internal architecture of the bone, the effects imposed on adjacent structures, being a highly useful tool with easy availability and less cost for accurate 
Table 1 Detailed comparison of seven reported cases from the literature

\begin{tabular}{|c|c|c|c|c|c|}
\hline Author and Year & Age & Sex & Site and size & $\begin{array}{l}\text { Radiological } \\
\text { features }\end{array}$ & $\begin{array}{l}\text { Histopathological } \\
\text { features }\end{array}$ \\
\hline Kuru $1911^{a}$ & - & - & - & - & \\
\hline $\begin{array}{l}\text { Tongdee and } \\
\text { Ganggakavin, } 1978^{a}\end{array}$ & - & - & - & - & - \\
\hline $\begin{array}{l}\text { Stevenson and } \\
\text { Austin, } 1990\end{array}$ & $47 y$ & Female & $\begin{array}{l}\text { Left mandibular third molar alveolar } \\
\text { crest region, approximately } 1 \mathrm{~cm} \text { in } \\
\text { size. }\end{array}$ & $\begin{array}{l}\text { Intraoral periapical } \\
\text { radiograph showed } \\
\text { well-defined } \\
\text { unilocular } \\
\text { radiolucency. }\end{array}$ & $\begin{array}{l}\text { Follicular and } \\
\text { acanthomatous types }\end{array}$ \\
\hline Shetty et al, 2010 & $11 \mathrm{y}$ & Male & $\begin{array}{l}\text { Left mandibular anterior region, of } \\
\text { size } 3 \mathrm{~cm} \text {. }\end{array}$ & $\begin{array}{l}\text { The panoramic } \\
\text { view showed large } \\
\text { unilocular } \\
\text { radiolucency. }\end{array}$ & Plexiform type \\
\hline Sanjay et al, 2011 & $45 y$ & Male & $\begin{array}{l}\text { Right anterior region of the } \\
\text { mandible of size } 3.5 \times 3.5 \mathrm{~cm} \text {. }\end{array}$ & $\begin{array}{l}\text { The intraoral } \\
\text { periapical } \\
\text { radiograph showed } \\
\text { a multilocular soap } \\
\text { bubble } \\
\text { appearance. }\end{array}$ & Follicular type \\
\hline Holikatti et al, 2015 & $50 \mathrm{y}$ & Female & $\begin{array}{l}\text { The lingual aspect of the right } \\
\text { posterior mandibular alveolar ridge } \\
\text { region, approximately } 3 \times 3 \mathrm{~cm} \text { in } \\
\text { size. }\end{array}$ & $\begin{array}{l}\text { The panoramic } \\
\text { view revealed } \\
\text { irregular } \\
\text { multilocular } \\
\text { radiolucency. }\end{array}$ & Acanthomatous type \\
\hline Tabatabaei et al, 2014 & $41 \mathrm{y}$ & Female & $\begin{array}{l}\text { Posterior region of the right third } \\
\text { molar tooth of size } 3 \times 3.5 \mathrm{~cm} \text {. }\end{array}$ & $\begin{array}{l}\text { The panoramic } \\
\text { view revealed soap } \\
\text { bubble multilocular } \\
\text { radiolucency with } \\
\text { well-defined } \\
\text { margins. }\end{array}$ & Follicular type \\
\hline The Present case report & $23 y$ & Male & $\begin{array}{l}\text { Right mandibular premolar, a molar } \\
\text { region of size } 4 \times 1 \mathrm{~cm} \text {. }\end{array}$ & $\begin{array}{l}\text { The panoramic } \\
\text { view showed well- } \\
\text { defined unilocular } \\
\text { radiolucency. } \\
\text { CBCT showed well- } \\
\text { defined } \\
\text { multilocular } \\
\text { hypodense lesion. }\end{array}$ & Plexiform type \\
\hline
\end{tabular}

${ }^{a}$ Detailed information is not available in the literature.

diagnosis of lesions of the jaws, especially to counteract such clinical dilemma by allowing the clinicians to better evaluate for best treatment outcomes.

\section{Declaration of Patient Consent}

The authors certify that they have obtained all appropriate patient consent forms. In the form, the patient's guardian has given his/her consent for the patient's images and other clinical information to be reported in the journal. The patient's guardian understands that the names and initials will not be published, and due efforts will be made to conceal their identity. Approval from the Institutional Review Board for publishing the same was also obtained.

\section{Financial Support and Sponsorship}

None.
Conflict of Interest

None declared.

\section{References}

1 Venkatesh E, Elluru SV. Cone beam computed tomography: basics and applications in dentistry. J Istanb Univ Fac Dent 2017;51(3, suppl 1):S102-S121

2 Whyte A, Boeddinghaus R, Matias MATJ. Diagnostic imaging principles and applications in head and neck pathology. In: Farah C, Balasubramaniam R, McCullough M, eds. Contemporary Oral Medicine. Cham: Springer; 2017:1-82

3 Wright JM, Vered M. Update from the $4^{\text {th }}$ Edition of the World Health Organization classification of head and neck tumours: odontogenic and maxillofacial bone tumors. Head Neck Pathol 2017;11(01):68-77

4 Kuru H. Ueber das Adamantinom. Zentralbl Allg Pathol 1911; 22:291-295

5 Masthan KMK, Anitha N, Krupaa J, Manikkam S. Ameloblastoma. J Pharm Bioallied Sci 2015;7(Suppl 1):S167-S170 
6 Shafer WG, Hine MK, Levy BM. A Textbook of Oral Pathology. Philadelphia: Saunders; 1983

7 Sanjay CJ, David CM, Kaul R, Bk R, Ramachandra P. Intraosseous ameloblastoma masquerading as exophytic growth: a case report. Imaging Sci Dent 2011;41(02):89-93

8 Martinelli-Kläy CP, Martinelli CR, Martinelli C, Macedo HR, Lombardi $\mathrm{T}$. Unusual imaging features of dentigerous cyst: a case report. Dent J (Basel) 2019;7(03):76

9 Nasim A, Mohan RPS, Nagaraju K, Malik SS, Goel S, Gupta S. Application of cone beam computed tomography gray scale values in the diagnosis of cysts and tumors. J Indian Acad Oral Med Radiol 2018;30:4-9

10 Holikatti K, Deore S, Gothe P, Shinde N. Ameloblastoma masquerading as gingival enlargement: a case report with un- usual presentation. J Oral Maxillofac Surg Med Pathol 2015; 27:588-591

11 Tabatabaei SH, Akhavan Karbasi MH, Danesh Ardekani M, Gholami N, Khabazian A. Central ameloblastoma with a peripheral ameloblastoma-like component: a case report. Iran J Med Sci 2014;39(05):480-483

12 Shetty RM, Rath S, Iyer V, Shetty S. Central plexiform ameloblastoma with exophytic growth: a rare case report with review of literature. Ann Essences Dent. 2010;2:106-111

13 Janardhanan M, Rakesh S, Savithri V, Aravind T. Peripheral ameloblastoma with neoplastic osseous invasion versus peripheral intraosseous ameloblastoma: A challenging diagnosis. J Oral Maxillofac Pathol 2018;22(03):396-400 